\title{
Clinical profile and management of outpatients with non-ischemic and non-hypertensive systolic heart failure: Analysis of the Polish DATA-HELP registry
}

\author{
Justyna M. Sokolska ${ }^{1,2}$, Beata Kurian³, Waldemar Banasiak ${ }^{2}$, \\ Ewa A. Jankowska ${ }^{1,2,4}$, Piotr Ponikowski ${ }^{1,2}$ \\ ${ }^{1}$ Department of Heart Diseases, Wroclaw Medical University, Wroclaw, Poland \\ ${ }^{2} 4^{\text {th }}$ Military Hospital, Cardiology Department, Centre for Heart Diseases, Wroclaw, Poland \\ ${ }^{3}$ Merck Serono, Warsaw, Poland \\ ${ }^{4}$ Laboratory for Applied Research on Cardiovascular System, Department of Heart Diseases, \\ Wroclaw Medical University, Wrocław, Poland
}

\begin{abstract}
Background: Although coronary artery disease and arterial hypertension are the most common etiologies underlying heart failure (HF), there are still many patients present with non-ischemic and non-hypertensive HF whose management remains very challenging. In this research study the clinical profile and applied treatment of patients with HF without coronary artery disease or hypertension versus patients with known etiology of HF (ischemic/hypertensive) were compared.

Methods: Clinical data about 5563 patients with stable systolic HF were obtained from prospective multicenter DATA-HELP registry performed between October and December 2009 in ambulatory clinics in Poland, in which 500 cardiologists and 290 general practitioners participated.

Results: Heart failure of non-ischemic and non-hypertensive etiology which affected $10 \%$ of all patients and was particularly frequent in younger patients, both in women: < 50 years old 42\%; 50-65 years old 12\%; > 65 years old 7\%; and men: < 50 years old 47\%; 50-65 years old 10\%; > 65 years old 5\%; $p<0.0001$. Patients with non-ischemic and non-hypertensive HF were characterized by younger age, fewer co-morbidities, shorter duration of HF and, surprisingly, more advanced HF. Patients in this group were less likely to have received life-prolonging treatment in HF recommended by European Society of Cardiology (ESC) and more often required symptomatic management. Similarly, they were more likely to have implanted CRT-D and ICD.

Conclusions: Heart failure of non-ischemic and non-hypertensive origin affects particularly young patients. These patients, despite suffering from more advanced HF are not optimally managed according to ESC guidelines. (Cardiol J 2018; 25, 4: 512-520)
\end{abstract}

Key words: DATA-HELP registry, heart failure with reduced ejection fraction, non-ischemic heart failure, Poland, systolic heart failure

\section{Introduction}

Heart failure (HF) is a clinical syndrome with many different underlying etiologies such as coronary artery disease, hypertension, myocarditis, valvular heart disease, arrhythmias, alcoholism, lysosomal storage diseases or amyloidosis [1-5].

Despite the fact that there have been substantial improvements in the management of $\mathrm{HF}$ in recent years, $\mathrm{HF}$ continues to encounter problems

Address for correspondence: Dr. Justyna M. Sokolska, Department of Heart Diseases, Wroclaw Medical University, ul. Weigla 5, 53-114 Wroclaw, Poland, tel: +48 261660 279, fax: +48 261660 250, e-mail: justynamsokolska@gmail.com Received: 15.05.2016 Accepted: 02.08.2016 
with high mortality, morbidity and an increasing rate of recurrent hospitalizations due to decompensated chronic HF [1, 6-9]. Therefore, currently a key issue is to optimize outpatient treatment of HF. The role of ambulatory treatment and follow-up provided by general practitioners and outpatient cardiac clinics cannot be underestimated in an effective rapid response to first signs of decompensation and in optimization of pharmacotherapy to slow down HF progression.

Thanks to clinical trials including patients with ischemic and hypertensive etiology of HF, we have implemented European Society of Cardiology (ESC) guidelines helpful in managing patients with $\mathrm{HF}$ according to the evidence based medicine. However, in contrary to well-established treatment of patients with ischemic and hypertensive origin of HF, there is a lack of clinical trials on other HF etiologies, and accordingly their management appears to be less clear [1].

The aim of this study was to investigate the Polish population of outpatients with systolic HF and to compare the clinical profile and applied treatment in patients with non-ischemic, nonhypertensive $\mathrm{HF}$ versus patients with ischemic or hypertensive etiology of HF.

\section{Methods}

\section{Study population and protocol}

A prospective multicenter DATA-HELP (DiAgnotic and TherApeutic methods used in patients with systolic HEart Failure Living in Poland) study was performed between October and December 2009 in Poland. Stratified randomization was conducted by Cegedim Strategic Data among all general practitioners (GPs) and cardiologists working in outpatient clinics with the algorithm based on the generation of pseudorandom numbers according to Wichman and Hill [10]. A random sample of physicians (500 cardiologists and $290 \mathrm{GPs}$ ) were invited to complete a questionnaire regarding the clinical status, medical history, administered diagnostic tests, applied therapy, recent hospitalizations and outpatient visits in 10 consecutive patients with systolic HF. Physicians were instructed to recruit patients with stable systolic $\mathrm{HF}$ and made responsible for the complex management of their treatment.

Recruited patients had to fulfil the following inclusion criteria:

- age $\geq 18$ years;

- clinical diagnosis of HF based on current European recommendations;

- left ventricular ejection fraction $(\mathrm{LVEF}) \leq 45 \%$;
- outpatient visit from October to December 2009.

This investigation conformed with the principles outlined in the Declaration of Helsinki. The study protocol was registered and approved by all involved ethics committees.

Detailed clinical data about information obtained from the questionnaires were completed by cardiologists and general practitioners about their outpatients with stable systolic HF are contained in the paper 'Comparison of clinical profile and management of outpatients with HF with reduced LVEF treated by general practitioners and cardiologist in contemporary Poland: the results from the DATA-HELP registry' Jankowska et al. (paragraph 2.2. Information obtained) [11]. Additionally, information about the number and kind of hospitalizations (urgent vs. planned; in cardiac vs. in other departments) and outpatient visits (in internal medicine vs. cardiac clinics vs. general practitioner practice vs. other specialized outpatient clinics) within 12 months preceding the study was obtained.

\section{Studied groups}

All outpatients with stable systolic HF recruited into the DATA-HELP registry were divided into three groups according to the etiology of $\mathrm{HF}$ : - patients with non-ischemic, non-hypertensive etiology (study group, in which the background of hypertensive and ischemic heart disease was excluded by their GP/cardiologist);

- patients with ischemic etiology (with coronary artery disease as a major underlying etiology of $\mathrm{HF}$, with previous myocardial infarction and/ or after revascularization - percutaneous coronary intervention [PCI] or coronary artery bypass grafting [CABG]);

- patients with arterial hypertension without concomitant coronary artery disease.

\section{Statistical analyses}

Continuous variables were expressed as mean \pm standard deviations when they were normally distributed or medians with lower and upper quartiles for variables with a skewed distribution. The categorized variables were presented as numbers with percentages. The statistical significance of differences between the groups were tested using analysis of variance (Kruskal-Wallice test), Student's t-test, or the $\chi^{2}$ test, where appropriate.

A value of $\mathrm{p}<0.05$ was considered statistically significant.

Statistical analyses were performed using STATISTICA 10 data analysis software system (StatSoft, Inc). 


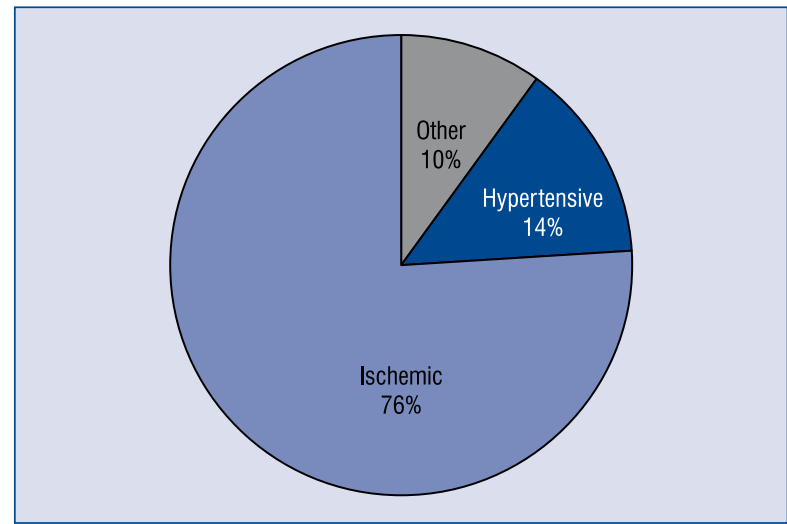

Figure 1. Distribution of etiology in studied group of patients with systolic heart failure.

\section{Results}

5563 outpatients with systolic HF were enrolled in the study - 59\% data (3300 patients) came from outpatient cardiology practices and $34 \%$ (1895 patients) from GPs. 10\% (546) of patients had etiologies other than ischemic and hypertensive, whereas in $76 \%$ of patients coronary artery disease was the leading cause of HF (Fig. 1). Both in men and women, the prevalence of non-ischemic and non-hypertensive $\mathrm{HF}$ decreased with the increasing age. Among younger patients ( $<50$ years old) every second patient with systolic HF had neither hypertensive nor ischemic heart disease (Figs. 2, 3).

In the non-ischemic and non-hypertensive groups there were patients with a shorter duration of the disease than in the ischemic group (Table 1). Patients in non-ischemic and non-hypertensive group were characterized by younger age and fewer co-morbidities (diabetes mellitus type 2, previous stroke/transient ischemic attack, chronic obstructive pulmonary disease/asthma). In this group patients experienced more advanced $\mathrm{HF}$, here defined as more severe symptoms of HF classified as New York Heart Association (NYHA) class III or IV, on physical examination (pulmonary congestion, hepatomegaly, jugular vein distension, third heart sounds) and LVEF < 20\% (Table 1).

Patients with non-ischemic and non-hypertensive HF received beta- blockers less frequently and angiotensin converting enzyme inhibitor/ /angiotensin receptor blocker (ACEI/ARB) with lower target doses. In contrast, they received more frequent mineralocorticoid receptor antagonists (MRA), but without differences in target doses of MRA between studied groups. Patients with nonischemic and non-hypertensive HF more often

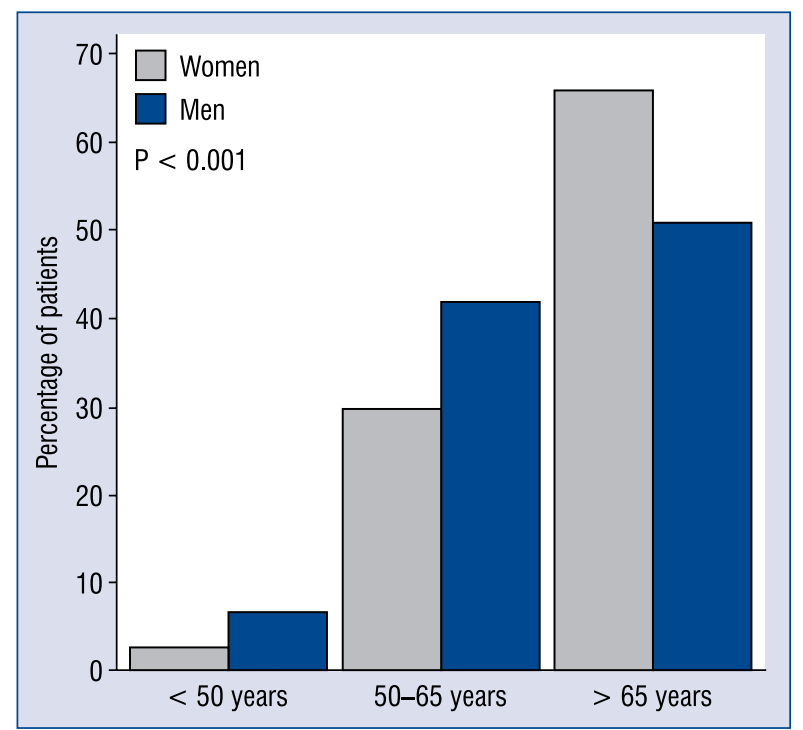

Figure 2. Age and gender distribution of outpatients with stable systolic heart failure $(n=5563)$.

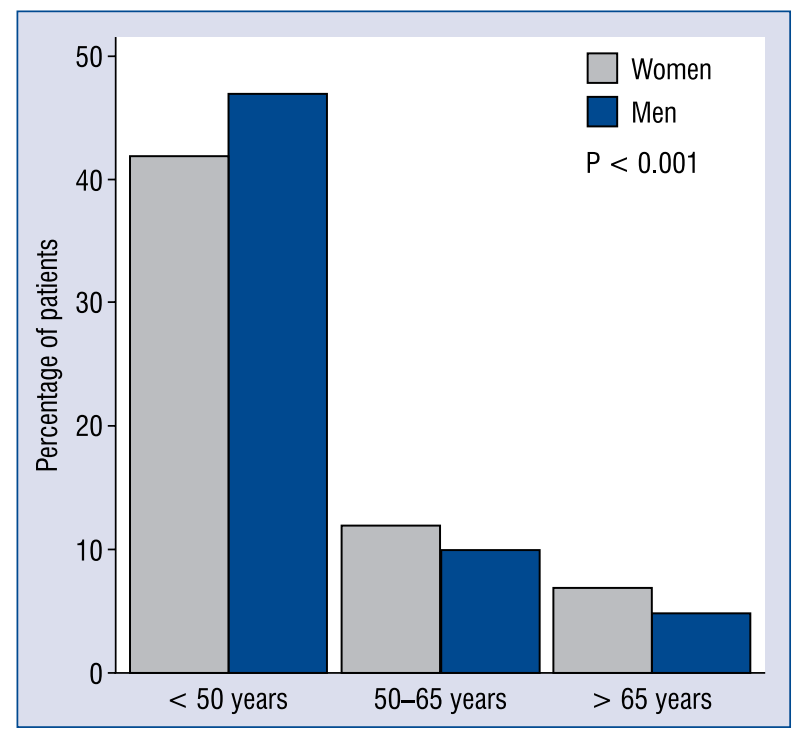

Figure 3. The prevalence of non-ischemic and non-hypertensive etiology of heart failure according to age and gender of patients with stable systolic heart failure ( $n=5563$ ).

needed symptomatic treatment with loop diuretics and digoxin and had cardiac resynchronization therapy (CRT) and implanted cardioverter-defibrillator (ICD) implanted in contrast to patients from other groups (Table 2 ).

Evaluation of patients' past medical history revealed that in the group of patients with nonischemic and non-hypertensive etiology of $\mathrm{HF}$ 
Table 1. Baseline clinical characteristics, co-morbidities and signs of heart failure in three groups of patients: with non-ischemic and non-hypertensive etiology, with hypertensive and non-ischemic etiology, with ischemic etiology.

\begin{tabular}{|c|c|c|c|c|c|}
\hline \multirow[t]{3}{*}{ Parameters } & \multicolumn{3}{|c|}{ Patients with systolic HF ( $n=5563$ ) } & \multirow[t]{3}{*}{$\chi^{2}$} & \multirow[t]{3}{*}{$\mathbf{P}$} \\
\hline & \multicolumn{3}{|c|}{ Studied groups } & & \\
\hline & $\begin{array}{c}\text { Non-ischemic, } \\
\text { non-hypertensive } \\
\text { HF (n=546; } 10 \%)\end{array}$ & $\begin{array}{c}\text { Hypertensive } \\
\text { non-ischemic HF } \\
(\mathrm{n}=764 ; 14 \%)\end{array}$ & $\begin{array}{c}\text { Ischemic HF } \\
\text { (n= 4253; } 76 \%)\end{array}$ & & \\
\hline \multicolumn{6}{|l|}{ Baseline characteristics } \\
\hline Women & $191(36)^{\text {aaa }}$ & $371(49)^{\mathrm{bbb}}$ & $1441(35)$ & 61 & $<0.0001$ \\
\hline Age [years] & $60[50-69]^{\text {aaa }}$ & $67[59-75]^{\mathrm{bbb}}$ & $69[61-76]^{\mathrm{ccc}}$ & 126 & $<0.0001$ \\
\hline $\mathrm{BMI}\left[\mathrm{kg} / \mathrm{m}^{2}\right]$ & $27[24-29]^{\text {aaa }}$ & $28[26-31]$ & $28[26-30]$ & 40 & $<0.0001$ \\
\hline Obesity: $\mathrm{BMI}>30 \mathrm{~kg} / \mathrm{m}^{2}$ & $106(20 \%)^{\text {aаa }}$ & $243(33 \%)$ & $1217(30 \%)^{\mathrm{ccc}}$ & 26 & $<0.0001$ \\
\hline NYHA: III + IV & $244(47 \%)^{a}$ & $198(41 \%)$ & $1412(34 \%)^{\mathrm{ccc}}$ & 2 & 0.002 \\
\hline Heart rate $\geq 70 \mathrm{bpm}$ & $399(74 \%)^{\text {aa }}$ & $610(80 \%)^{\mathrm{bbb}}$ & $2980(71 \%)$ & 30 & $<0.001$ \\
\hline $\begin{array}{l}\mathrm{SBP}>140 \text { or DBP }>90 \mathrm{~mm} \mathrm{Hg} \\
\text { on the outpatient's office visit }\end{array}$ & $101(19 \%)^{\text {aаa }}$ & $359(48 \%)^{\mathrm{bbb}}$ & $1643(39 \%)^{\mathrm{ccc}}$ & 117 & $<0.0001$ \\
\hline HF diagnosis [years] & $4[2-7]$ & $4[2-7]^{\mathrm{bb}}$ & $4[2-9]^{c c}$ & 10 & 0.008 \\
\hline LVEF [\%] & $33[25-40]^{\text {aaa }}$ & 40 [34-41] & 38 [31-40] & 64 & $<0.0001$ \\
\hline LVEF $\leq 35 \%$ & $337(62 \%)^{\text {aaa }}$ & $281(37 \%)$ & $1792(42 \%)^{\mathrm{ccc}}$ & 91 & $<0.0001$ \\
\hline \multicolumn{6}{|l|}{ Co-morbidities } \\
\hline Hypertension & $0(0 \%)^{\text {aаa }}$ & $764(100 \%)^{\mathrm{bbb}}$ & $3083(72 \%)^{\mathrm{ccc}}$ & 1587 & $<0.0001$ \\
\hline Previous stroke/TIA & $65(12 \%)^{\text {aa }}$ & $133(17 \%)$ & $797(19 \%)^{c c c}$ & 16 & $<0.001$ \\
\hline Atrial fibrillation & $243(45 \%)$ & $365(48 \%)^{\mathrm{bbb}}$ & $1303(31 \%)^{c c c}$ & 112 & $<0.0001$ \\
\hline Cancer & $14(3 \%)$ & $14(2 \%)$ & $108(3 \%)$ & 1 & NS \\
\hline COPD/asthma & $63(12 \%)^{\text {aa }}$ & $130(17 \%)^{b}$ & $582(14 \%)$ & 9 & 0.01 \\
\hline Previous AMI & $0^{\text {aaa }}$ & 0 & $3075(72 \%)^{\mathrm{ccc}}$ & 2117 & $<0.0001$ \\
\hline DM type 2 & $76(14 \%)^{\text {aаa }}$ & $236(31 \%)^{\mathrm{bb}}$ & $1566(37 \%)^{\mathrm{ccc}}$ & 117 & $<0.0001$ \\
\hline \multicolumn{6}{|l|}{ Signs of heart failure } \\
\hline Lung congestion & $76(14 \%)$ & $85(11 \%)^{b}$ & $361(8 \%)^{\mathrm{ccc}}$ & 20 & $<0.001$ \\
\hline Peripheral oedema & $(20 \%)$ & $(22 \%)^{\mathrm{bb}}$ & $(17 \%)$ & 10 & 0.008 \\
\hline Hepatomegaly & $188(34 \%)^{\text {aaa }}$ & $196(26 \%)$ & $1080(25 \%)^{\mathrm{ccc}}$ & 21 & $<0.0001$ \\
\hline Jugular vein distension & $131(24 \%)^{\text {aa }}$ & $138(18 \%)$ & $672(16 \%)^{\mathrm{ccc}}$ & 24 & $<0.0001$ \\
\hline Third heart sound & $125(23 \%)^{a}$ & $138(18 \%)$ & $712(17 \%)^{\mathrm{ccc}}$ & 13 & 0.002 \\
\hline
\end{tabular}

$\mathrm{AMI}$ - acute myocardial infarction; BMI — body mass index; COPD — chronic obstructive pulmonary disease; DBP - diastolic blood pressure DM - diabetes mellitus; HF — heart failure; LVEF — left ventricular ejection fraction; NS — non-significant; NYHA - New York Heart Association classification; SBP - systolic blood pressure; TIA — transient ischemic attack

Results are presented as a number of patients (and percentage) or median [with lower and upper quantil].

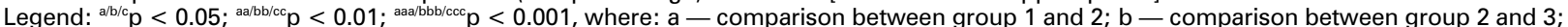
c - comparison between group 1 and 3. Lack of the letter "a/b/c" in some tables cells means that there is no significant difference between groups ( $p$ was non-significant for that comparison)

there were more cardiac hospitalizations (both urgent and planned) than in hypertensive group, however there was no significant difference when compared with the ischemic group. There were differences in all non-cardiac hospitalizations and the total number of hospital admissions. Patients with non-ischemic and non-hypertensive HF were less often seen in outpatient clinics than other groups (Table 3).

\section{Discussion}

The major finding of this study revealed HF of non-ischemic and non-hypertensive origin 
Table 2. Comparison of treatment in systolic heart failure between three studied groups of patients: with non-ischemic and non-hypertensive etiology, with hypertensive and non-ischemic etiology, and with ischemic etiology.

\begin{tabular}{|c|c|c|c|c|c|}
\hline \multirow[t]{3}{*}{ Parameters } & \multicolumn{3}{|c|}{$\begin{array}{l}\text { Treatment of patients with systolic heart failure } \\
\qquad(\mathrm{n}=5563)\end{array}$} & \multirow[t]{3}{*}{$\chi^{2}$} & \multirow[t]{3}{*}{$\mathbf{P}$} \\
\hline & \multicolumn{3}{|c|}{ Studied groups } & & \\
\hline & $\begin{array}{c}\text { Non-ischemic, } \\
\text { non-hypertensive } \\
\text { HF }(n=546 ; 10 \%)\end{array}$ & $\begin{array}{l}\text { Hypertensive, } \\
\text { non-ischemic HF } \\
(\mathrm{n}=764 ; 14 \%)\end{array}$ & $\begin{array}{c}\text { Ischemic HF } \\
\text { (n = 4253; 76\%) }\end{array}$ & & \\
\hline \multicolumn{6}{|l|}{ Revascularization } \\
\hline $\mathrm{PCl}$ & $0(0 \%)^{\text {aaa }}$ & $0(0 \%)^{\mathrm{bbb}}$ & $2205(52 \%)$ & 1125 & $<0.0001$ \\
\hline CABG & $0(0 \%)^{\text {aаa }}$ & $0(0 \%)^{\mathrm{bbb}}$ & $782(18 \%)$ & 280 & $<0.0001$ \\
\hline \multicolumn{6}{|l|}{ Implantable devices } \\
\hline ICD and/or CRT & $91(17 \%)^{\text {aa }}$ & $52(7 \%)$ & $359(8 \%)^{\mathrm{cc}}$ & 45 & $<0.0001$ \\
\hline CRT & $47(9 \%)^{\text {aаa }}$ & $22(3 \%)$ & $109(3 \%)^{\mathrm{ccc}}$ & 57 & $<0.0001$ \\
\hline Pacemaker & $29(5 \%)$ & $40(5 \%)$ & $260(6 \%)$ & 1 & NS \\
\hline \multicolumn{6}{|l|}{ Medications } \\
\hline ACEI/ARB & $518(90 \%)^{\text {aa }}$ & $793(94 \%)$ & $4399(95 \%)^{c c c}$ & 17 & $<0.0001$ \\
\hline ACEI/ARB - the target dose & $65(20 \%)^{\text {aаa }}$ & $168(37 \%)$ & $924(36 \%)^{\mathrm{ccc}}$ & 340 & $<0.001$ \\
\hline Beta-blocker & $522(96 \%)$ & $726(95 \%)^{b}$ & $4113(97 \%)$ & 6 & 0.04 \\
\hline Beta-blocker - the target dose & $65(13 \%)$ & $94(14 \%)$ & $468(12 \%)$ & 2 & NS \\
\hline MRA & $382(70 \%)^{\text {aaa }}$ & $447(59 \%)$ & $2539(60 \%)^{c c c}$ & 23 & $<0.0001$ \\
\hline MRA - the target dose & $110(21 \%)$ & $141(19 \%)$ & $742(18 \%)$ & 2 & NS \\
\hline Statin & $262(48 \%)^{\text {aаa }}$ & $510(67 \%)^{\mathrm{bbb}}$ & $3791(89 \%)^{\mathrm{ccc}}$ & 696 & $<0.0001$ \\
\hline Calcium channel blocker & $50(9 \%)^{\text {aаa }}$ & $218(29 \%)$ & $1083(26 \%)^{c c c}$ & 79 & $<0.0001$ \\
\hline Loop diuretic & $379(69 \%)^{\mathrm{a}}$ & $487(64 \%)$ & $1617(62 \%)^{\mathrm{ccc}}$ & 13 & 0.001 \\
\hline Loop diuretics $\geq 100 \mathrm{mg} /$ day & $31(6 \%)$ & $36(5 \%)$ & $155(4 \%)^{c}$ & 7 & 0.03 \\
\hline Thiazide diuretic & $127(23 \%)^{\text {aаa }}$ & $242(32 \%)^{\mathrm{bbb}}$ & $1042(25 \%)$ & 19 & $<0.0001$ \\
\hline Both diuretics & $463(85 \%)$ & $667(87 \%)^{\mathrm{bbb}}$ & $3408(80 \%)^{\mathrm{cc}}$ & 26 & $<0.0001$ \\
\hline Digoxin & $189(35 \%)^{\text {aаa }}$ & $196(26 \%)^{\mathrm{bbb}}$ & $763(18 \%)^{\mathrm{ccc}}$ & 96 & $<0.0001$ \\
\hline Nitrates & $37(7 \%)$ & $57(8 \%)^{\mathrm{bbb}}$ & $1130(27 \%)^{\mathrm{ccc}}$ & 220 & $<0.0001$ \\
\hline Antiplatelet drugs & $248(45 \%)^{\text {aаa }}$ & $437(57 \%)^{\mathrm{bbb}}$ & $3564(84 \%)^{\mathrm{ccc}}$ & 576 & $<0.0001$ \\
\hline
\end{tabular}

ACEI — angiotensin converting enzyme inhibitor; ARB — angiotensin receptor blocker; CABG — coronary artery bypass grafting; CRT-D cardiac resynchronization therapy defibrillator with pacing capabilities; HF — heart failure; ICD — implantable cardiac device; MRA — mineralocorticoid receptor antagonist; NS - non-significant; $\mathrm{PCl}$ - percutaneous coronary intervention

Results are presented as a number of patients (and percentage) or median [with lower and upper quantil].

Legend: ${ }^{a / b / c} p<0.05 ;{ }^{a / / b / c c} p<0.01$; ${ }^{\text {aa//bbb/ccc } p<0.001, ~ w h e r e: ~} a-$ comparison between group 1 and $2 ;$; - comparison between group 2 and 3 ; $\mathrm{c}$ - comparison between group 1 and 3. Lack of the letter "a/b/c" in some tables cells means that there is no significant difference between groups ( $p$ was non-significant for that comparison)

predominantly affects young adults, who despite suffering from more advanced $\mathrm{HF}$ than patients with ischemic or hypertensive etiology of HF, are not optimally managed, possibly due to the lack of clinical trials and evidence based guidelines on how to treat patients with non-ischemic and nonhypertensive $\mathrm{HF}$.

Jankowska et al. [11] based on the same DATA-HELP registry has elegantly described some observed differences between the clinical profile and management of outpatients with HF supervised by GPs versus those treated by cardiologists. They observed that patients treated by GPs were older, had more comorbidities, less commonly received beta-blocker and MRA, less often had implantable devices (ICD and CRT) and underwent coronary revascularization. Therefore, these findings should also be taken into consideration, as they may play a role in optimization and improvement in management of outpatients with HF.

Ischemic heart disease (defined as a history of myocardial infarction, revascularization by PCI and/or CABG or coronary artery disease confirmed in coronarography), either alone (28\%) or together 
Table 3. Number of hospitalizations and outpatient visits within 12 preceding months in three groups of patients: with non-ischemic and non-hypertensive etiology, with hypertensive and non-ischemic etiology, with ischemic etiology.

\begin{tabular}{|c|c|c|c|c|c|}
\hline \multirow[t]{3}{*}{ Parameters } & \multicolumn{3}{|c|}{$\begin{array}{l}\text { Hospitalizations and outpatients' visits } \\
\text { within } 1 \text { preceding year } \\
\text { Patients with systolic HF (n= 5563) }\end{array}$} & \multirow[t]{3}{*}{$\chi^{2}$} & \multirow[t]{3}{*}{$\mathbf{P}$} \\
\hline & \multicolumn{3}{|c|}{ Studied groups } & & \\
\hline & $\begin{array}{c}\text { Non-ischemic, } \\
\text { non-hypertensive } \\
\text { HF (n=546; } 10 \%)\end{array}$ & $\begin{array}{l}\text { Hypertensive, } \\
\text { non-ischemic HF } \\
(\mathrm{n}=764 ; 14 \%)\end{array}$ & $\begin{array}{c}\text { Ischemic HF } \\
(n=4253 ; 76 \%)\end{array}$ & & \\
\hline \multicolumn{6}{|l|}{ Hospitalizations } \\
\hline Urgent, in cardiac department & $1.31 \pm 1.15^{\mathrm{aa}}$ & $1.10 \pm 1.11^{\mathrm{bb}}$ & $1.26 \pm 1.12$ & 15 & 0.0004 \\
\hline Planned, in cardiac department & $1.09 \pm 0.96^{\mathrm{aa}}$ & $0.91 \pm 0.95^{\mathrm{b}}$ & $1.00 \pm 1.00$ & 10 & 0.007 \\
\hline $\begin{array}{l}\text { All (urgent and planned), } \\
\text { in cardiac department }\end{array}$ & $2.16 \pm 1.71^{\text {aа }}$ & $1.75 \pm 1.68^{\mathrm{bbb}}$ & $2.14 \pm 1.84$ & 18 & 0.0001 \\
\hline Urgent, in other departments & $0.93 \pm 1.05$ & $1.00 \pm 1.03$ & $1.04 \pm 1.10$ & 3 & 0.2 \\
\hline Planned, in other departments & $0.70 \pm 0.90^{\mathrm{a}}$ & $0.86 \pm 0.96$ & $0.77 \pm 0.93$ & 6 & 0.04 \\
\hline $\begin{array}{l}\text { All (urgent and planned), } \\
\text { in other departments }\end{array}$ & $1.40 \pm 1.53$ & $1.51 \pm 1.54$ & $1.52 \pm 1.67$ & 1 & 0.6 \\
\hline All hospitalizations & $3.34 \pm 2.86$ & $2.93 \pm 2.65$ & $3.26 \pm 3.04$ & 3 & 0.2 \\
\hline \multicolumn{6}{|l|}{ Outpatients visits } \\
\hline In internal medicine clinics & $1.93 \pm 1.63^{\text {aаa }}$ & $2.54 \pm 1.58$ & $2.50 \pm 1.62^{\mathrm{ccc}}$ & 37 & $<0.0001$ \\
\hline In cardiac clinics & $2.90 \pm 1.28^{\mathrm{aa}}$ & $2.71 \pm 1.29^{b}$ & $2.85 \pm 1.33$ & 7 & 0.03 \\
\hline $\begin{array}{l}\text { In general practitioner's } \\
\text { practice }\end{array}$ & $2.96 \pm 1.50$ & $3.10 \pm 1.55$ & $3.20 \pm 1.47^{\mathrm{cc}}$ & 11 & 0.004 \\
\hline In other specialists' clinics & $1.20 \pm 1.39^{\text {aаa }}$ & $1.78 \pm 1.50$ & $1.73 \pm 1.53^{\mathrm{ccc}}$ & 36 & $<0.0001$ \\
\hline All outpatinets' visits & $8.19 \pm 3.77^{\text {aаa }}$ & $9.39 \pm 4.12$ & $9.58 \pm 4.21^{\mathrm{ccc}}$ & 28 & $<0.0001$ \\
\hline
\end{tabular}

$\mathrm{HF}$ - heart failure; Results are presented as a mean number of hospitalizations/visits (with standard deviations).

Legend: ${ }^{a / b / c} p<0.05 ;{ }^{\text {aa/bb/cc }} p<0.01 ;{ }^{\text {aaa/bbb/ccc }} p<0.001$, where: a - comparison between group 1 and 2 ; b - comparison between group 2 and 3; c - comparison between group 1 and 3 . Lack of the letter "a/b/c" in some of the table cells means that there is no significant difference between groups ( $p$ was non-significant for that comparison).

with hypertension $(72 \%)$, is the most common cause of $\mathrm{HF}$ and is present in three-fourths of outpatients with chronic HF. It is noteworthy here to mention the study from McMurray et al. [2], in which they raised difficulties with clear adjustment of primary etiology of HF in patients with multiple potential causes (especially with coexisting ischemic heart disease and hypertension). Hypertension, without concomitant diagnosis of ischemic heart disease, was the second most common cause of HF. In comparison with the Rywik et al. study [12] noteing the prevalence of coexisting ischemic and hypertensive etiology of HF which has remained at a similar level in Poland for more than 10 years (55\% in the present study vs. $53 \%$ ), while ischemic heart disease alone appears less often to be a primary cause of HF than in the previous decade ( $21 \%$ vs. $26 \%$ ). Nowadays hypertension as a primary cause of $\mathrm{HF}$ is more common ( $14 \% \mathrm{vs.}$ $8 \%$ ), whereas non-ischemic and non-hypertensive etiology of HF has slightly decreased currently (10\% vs. $12 \%)$ [12].

In the studied registry, non-ischemic and nonhypertensive etiology of $\mathrm{HF}$ was found in every tenth outpatient with systolic HF and this prevalence increased up to $46 \%$ in patients below 50 years of age.

Among patients with non-ischemic and nonhypertensive HF there are patients suffering from cardiac arrhythmias, valve dysfunction, cardiomyopathy (dilated, alcoholic, toxic, idiopathic etc.), pericardial disease (i.e. constrictive pericarditis) or past infections (viral myocarditis, rheumatic fever, HIV, Chagas disease) $[2,3,13]$. Unfortunately, the diagnostic process to discover etiology of $\mathrm{HF}$ often only results in eliminating some of the possible causes i.e. ischemic, hypertensive and arrhythmic and valve dysfunction. Thus, many patients are labelled as 'non-ischemic and non-hypertensive' $\mathrm{HF}$, without finding the underlying cause of $\mathrm{HF}$ and as a consequence, it could be difficult, if not 
impossible to treat them effectively. Taking into account possible causes of $\mathrm{HF}$ in the group of patients with non-ischemic and non-hypertensive $\mathrm{HF}$ in this study it was found that $45 \%$ of patients had a history of atrial fibrillation (more than in ischemic group $-31 \%, \mathrm{p}<0.0001$, but similar to hypertensive group - $48 \%$ ), $27 \%$ had valve dysfunction (more than in the ischemic group $-10 \%$, $\mathrm{p}<0.001$, but less than in the hypertensive group $-33 \%, \mathrm{p}<0.05$; however there is an important limitation in the interpretation of this data from the registry - there was no information about location and severity of valve dysfunction), 35\% had possible post-infectious etiology (more than in ischemic $-1 \%$ and hypertensive group $-12 \%$, all $\mathrm{p}<0.001$ ) and $10 \%$ were alcoholics (again more than in ischemic $-2.5 \%$ and hypertensive group $-3 \%$, all $\mathrm{p}<0.001)$. After exclusions of the aforementioned diagnosed and potential causes of $\mathrm{HF}$ in 108 patients (2\% of all studied patients with $\mathrm{HF}$ and $20 \%$ of patients classified primary as non-ischemic and non-hypertensive etiology), no possible etiology has been found and can be classified as idiopathic HF. Especially in this population of patients with HF, it appears to be justified to perform more sophisticated investigations like cardiac magnetic resonance or even heart biopsy, however it must be pointed out, that these kinds of examinations should take place only in clinics with experience in performing and describing results of these procedures [14-24].

It appeared that only suggestions about diagnosis were obtained, without clear guidelines how treat patients with non-ischemic and nonhypertensive cause of HF.

The registry revealed that patients with nonischemic and non-hypertensive etiology were treated sub-optimally according to the latest ESC guidelines on treatment of HF with reduced LVEF [1]. Not only did fewer patients from this group receive ACEI/ARB (90\%), but they also rarely achieved the target dose of those medications (only 20\% of patients). Patients with non-ischemic and non-hypertensive HF were more frequently treated with MRA (70\%). There was however, no difference in achieving the target dose of MRA between the studied groups. Despite a great improvement in treatment and outcomes in patients with $\mathrm{HF}$ over the last two decades [25], there are still many problems in reaching the target doses of recommended medications in ambulatory practice dispite this issue having been widely discussed in the literature [26, 27]. In the group of patients with non-ischemic and non-hypertensive etiology reported more hospitalizations in cardiac departments than in the hypertensive group and fewer outpatient visits.

It was observed that despite substantial percentage of patients having indications for implantation of CRT/ICD device only $9 \%$ finally had such a device implanted. Of note, patients with nonischemic and non-hypertensive HF received ICD/ /CRT therapy twice as often than the two other group. Van Veldhuisen et al. [28] on the basis of the EUROMED Registry pointed out that implantable devices are underutilised in CHF patients with major differences across various countries (with the highest rate of ICD implants in Germany and the lowest rate was in Spain; data from Poland was not obtained). In the ESC-HF Pilot Survey performed in 12 European countries during the same time frame as the present study - from October 2009 to May 2010 - only $23 \%$ of patients with chronic HF had ICD/CRT implanted [29]. Also, in the recent PARADIGM-HF trial, despite careful selection of optimally managed patients, again $22 \%$ received CRT/ICD therapy [30].

\section{Limitation of the study}

An important limitation of this study, as in all registries performed on large populations in multicenter settings, is that it is linked with a questionnaire type study and has limited opportunities for data verification. It must be emphasized, that this study relied entirely on the judgement of physicians regarding the underlying etiology of $\mathrm{HF}$ in their patients. Therefore, as in all studies based on questionnaires, assumptions were taken that all data would be provided reliably according to the rules of Good Clinical Practice, including the selection of patients to be recruited for the registry as well as the reporting of all data.

Despite the aforementioned limitations, there is also a great advantage of these type of studies. They reflect a real-world clinical practice which can be confronted with the applicable guidelines, thus answering an important question: how do physicians treat ten consecutive patients with $\mathrm{HF}$ for whom they are fully responsible?

During the study design 7900 outpatients were expected to be included in the registry (by 500 cardiologists and 290 GPs), but completed data was obtained in just 5563 of those patients. Nevertheless, the big sample size allowed treating this population as representative of Polish outpatients with stable systolic heart failure. 


\section{Conclusions}

Currently in Poland every tenth patient with systolic HF has non-ischemic and non-hypertensive underlying etiology of $\mathrm{HF}$, with high prevalence in younger adults and in every second patient below 50 years old. Despite younger age and a low prevalence of comorbidities, patients with non-ischemic and non-hypertensive HF suffer from more advanced HF (defined as lower LVEF, NYHA class III or IV and signs of HF on physical examination) than patients with ischemic or hypertensive etiology. Patients with non-ischemic and non-hypertensive HF remain not optimally managed (according to the ESC guidelines for $\mathrm{HF}$ ) and more commonly require symptomatic treatment.

\section{Acknowledgements}

The DATA-HELP registry was funded by Merck Serono. All analyses were performed by the authors without any influence from the sponsor.

Conflicts of interest: EAJ, WB have received honoraria from Servier and Merck Serono; PP has received honoraria from Merck Serono; BK was an employee of Merck Serono; JMS reports no conflict of interest.

\section{References}

1. McMurray JJV, Adamopoulos S, Anker SD, et al. Task Force for the Diagnosis and Treatment of Acute and Chronic Heart Failure 2012 of the European Society of Cardiology, ESC Committee for Practice Guidelines. ESC guidelines for the diagnosis and treatment of acute and chronic heart failure 2012: The Task Force for the Diagnosis and Treatment of Acute and Chronic Heart Failure 2012 of the European Society of Cardiology. Developed in collaboration with the Heart Failure Association (HFA) of the ESC. Eur J Heart Fail. 2012; 14(8): 803-869, doi: 10.1093/eurjhf/ hfs105, indexed in Pubmed: 22828712.

2. McMurray JJ. Heart failure: Epidemiology, aetiology, and prognosis of heart failure. Heart. 2000; 83(5): 596-602, doi: 10.1136/ heart.83.5.596.

3. Cowie MR, Wood DA, Coats AJ, et al. Incidence and aetiology of heart failure; a population-based study. Eur Heart J. 1999; 20(6): 421-428, indexed in Pubmed: 10213345.

4. Linhart A, Elliott PM. The heart in Anderson-Fabry disease and other lysosomal storage disorders. Heart. 2007; 93(4): 528-535, doi: 10.1136/hrt.2005.063818, indexed in Pubmed: 17401074.

5. Quarta CC, Kruger JL, Falk RH. Cardiac Amyloidosis. Circulation. 2012; 126(12): e178-e182, doi: 10.1161/circulationaha.111.069195.

6. Gheorghiade M, Vaduganathan M, Fonarow GC, et al. Rehospitalization for heart failure: problems and perspectives. J Am Coll Cardiol. 2013; 61(4): 391-403, doi: 10.1016/j.jacc.2012.09.038, indexed in Pubmed: 23219302.
7. Giamouzis G, Kalogeropoulos A, Georgiopoulou V, et al. Hospitalization epidemic in patients with heart failure: risk factors, risk prediction, knowledge gaps, and future directions. J Card Fail. 2011; 17(1): 54-75, doi: 10.1016/j.cardfail.2010.08.010, indexed in Pubmed: 21187265.

8. McLaren DP, Jones R, Plotnik R, et al. Prior hospital admission predicts thirty-day hospital readmission for heart failure patients. Cardiol J. 2016; 23(2): 155-162, doi: 10.5603/CJ.a2016.0005, indexed in Pubmed: 26779968.

9. Tokatli A, Ural D. Previous hospitalizations predict both hospital readmissions and mortality in patients with heart failure. Cardiol J. 2016; 23(2): 224-224, doi: 10.5603/cj.2016.0020.

10. Wichmann BA, Hill ID. Generating good pseudo-random numbers. Computational Statistics \& Data Analysis. 2006; 51(3): 1614-1622, doi: 10.1016/j.csda.2006.05.019.

11. Jankowska EA, Kalicinska E, Drozd M, et al. Comparison of clinical profile and management of outpatients with heart failure with reduced left ventricular ejection fraction treated by general practitioners and cardiologists in contemporary Poland: the results from the DATA-HELP registry. Int J Cardiol. 2014; 176(3): 852-858, doi: 10.1016/j.ijcard.2014.08.005, indexed in Pubmed: 25156847.

12. Rywik TM, Rywik SL, Korewicki J, et al. Management of heart failure patients in Poland. Eur J Heart Fail. 2002; 4(2): 215-219, indexed in Pubmed: 11959052.

13. Howell EH, Cameron SJ. Neprilysin inhibition: A brief review of past pharmacological strategies for heart failure treatment and future directions. Cardiol J. 2016; 23(6): 591-598, doi: 10.5603/ CJ.a2016.0063, indexed in Pubmed: 27665860.

14. Kim EK, Chang SA, Choi JO, et al. Concordant and discordant cardiac magnetic resonance imaging delayed hyperenhancement patterns in patients with ischemic and non-ischemic cardiomyopathy. Korean Circ J. 2016; 46(1): 41-47, doi: 10.4070/ kcj.2016.46.1.41, indexed in Pubmed: 26798384.

15. Mavrogeni S, Markousis-Mavrogenis G, Markussis V, et al. The Emerging Role of Cardiovascular Magnetic Resonance Imaging in the Evaluation of Metabolic Cardiomyopathies. Horm Metab Res. 2015; 47(9): 623-632, doi: 10.1055/s-0035-1555913, indexed in Pubmed: 26197853.

16. Valbuena-López S, Hinojar R, Puntmann VO. Cardiovascular magnetic resonance in cardiology practice: A concise guide to image acquisition and clinical interpretation. Rev Esp Cardiol (Engl Ed). 2016; 69(2): 202-210, doi: 10.1016/j.rec.2015.11.011, indexed in Pubmed: 26778592.

17. Saeed M, Van TuA, Krug R, et al. Cardiac MR imaging: current status and future direction. Cardiovasc Diagn Ther. 2015; 5(4): 290-310, doi: 10.3978/j.issn.2223-3652.2015.06.07, indexed in Pubmed: 26331113.

18. Won E, Donnino R, Srichai MB, et al. Diagnostic accuracy of cardiac magnetic resonance imaging in the evaluation of newly diagnosed heart failure with reduced left ventricular ejection fraction. Am J Cardiol. 2015; 116(7): 1082-1087, doi: 10.1016/j. amjcard.2015.06.032, indexed in Pubmed: 26251006.

19. Bejar D, Colombo PC, Latif F, et al. Infiltrative cardiomyopathies. Clin Med Insights Cardiol. 2015; 9(Suppl 2): 29-38, doi: 10.4137/ CMC.S19706, indexed in Pubmed: 26244036.

20. Gonzalez JA, Kramer CM. Role of imaging techniques for diagnosis, prognosis and management of heart failure patients: cardiac magnetic resonance. Curr Heart Fail Rep. 2015; 12(4): 276-283, doi: 10.1007/s11897-015-0261-9, indexed in Pubmed: 26041670. 
21. Kuruvilla S, Adenaw N, Katwal AB, et al. Late gadolinium enhancement on cardiac magnetic resonance predicts adverse cardiovascular outcomes in nonischemic cardiomyopathy: a systematic review and meta-analysis. Circ Cardiovasc Imaging. 2014; 7(2): 250-258, doi: 10.1161/CIRCIMAGING.113.001144, indexed in Pubmed: 24363358.

22. Dominguez F, Kühl U, Pieske B, et al. Update on myocarditis and inflammatory cardiomyopathy: Reemergence of endomyocardial biopsy. Rev Esp Cardiol (Engl Ed). 2016; 69(2): 178-187, doi: 10.1016/j.rec.2015.10.015, indexed in Pubmed: 26795929.

23. Bennett MK, Gilotra NA, Harrington C, et al. Evaluation of the role of endomyocardial biopsy in 851 patients with unexplained heart failure from 2000-2009. Circ Heart Fail. 2013; 6(4): 676-684, doi: 10.1161/CIRCHEARTFAILURE.112.000087, indexed in Pubmed: 23733916.

24. Berthelot-Richer M, O'Connor K, Bernier M, et al. When should we consider the diagnosis of giant cell myocarditis? Revisiting "classic" echocardiographic and clinical features of this rare pathology. Exp Clin Transplant. 2014; 12(6): 565-568, doi: 10.6002/ ect.2013.0218, indexed in Pubmed: 24650294.

25. Loh JC, Creaser J, Rourke DA, et al. Temporal trends in treatment and outcomes for advanced heart failure with reduced ejection fraction from 1993-2010: findings from a university referral center. Circ Heart Fail. 2013; 6(3): 411-419, doi: 10.1161/CIRCHEARTFAILURE.112.000178, indexed in Pubmed: 23479563.

26. Maggioni AP, Anker SD, Dahlström U, et al. Heart Failure Association of the ESC. Are hospitalized or ambulatory patients with heart failure treated in accordance with European Society of Cardiology guidelines? Evidence from 12,440 patients of the ESC Heart Failure Long-Term Registry. Eur J Heart Fail. 2013; 15(10): 1173-1184, doi: 10.1093/eurjhf/hft134, indexed in Pubmed: 23978433.

27. Sosnowska-Pasiarska B, Bartkowiak R, Wożakowska-Kapłon B, et al. Population of Polish patients participating in the Heart Failure Pilot Survey (ESC-HF Pilot). Kardiol Pol. 2013; 71(3): 234-240, doi: 10.5603/KP.2013.0034, indexed in Pubmed: 23575777.

28. van Veldhuisen DJ, Maass AH, Priori SG, et al. Implementation of device therapy (cardiac resynchronization therapy and implantable cardioverter defibrillator) for patients with heart failure in Europe: changes from 2004 to 2008. Eur J Heart Fail. 2009; 11(12): 1143-1151, doi: 10.1093/eurjhf/hfp149, indexed in Pubmed: 19884129.

29. Maggioni AP, Dahlström U, Filippatos G, et al. Heart Failure Association of the European Society of Cardiology (HFA), Heart Failure Association of ESC (HFA). EURObservational Research Programme: the Heart Failure Pilot Survey (ESC-HF Pilot). Eur J Heart Fail. 2010; 12(10): 1076-1084, doi: 10.1093/eurjhf/ hfq154, indexed in Pubmed: 20805094.

30. McMurray JJV, Packer M, Desai AS, et al. PARADIGM-HF Investigators and Committees. Angiotensin-neprilysin inhibition versus enalapril in heart failure. N Engl J Med. 2014; 371(11): 993-1004, doi: 10.1056/NEJMoa1409077, indexed in Pubmed: 25176015. 